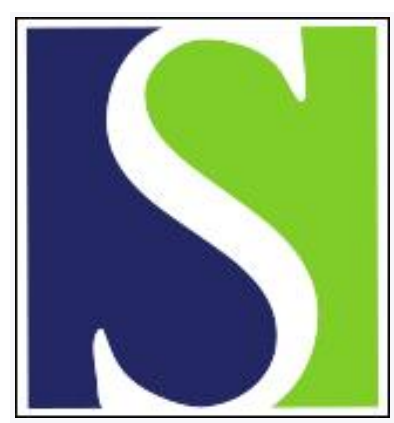

Scand J Work Environ Health 1985;11(6):417-425

https://doi.org/10.5271/sjweh.2205

Issue date: Dec 1985

Soft tissue disorders in the upper limbs of female garment workers.

by Punnett L, Robins JM, Wegman DH, Keyserling WM

This article in PubMed: www.ncbi.nlm.nih.gov/pubmed/4095519

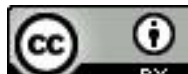




\title{
Soft tissue disorders in the upper limbs of female garment workers
}

\author{
by Laura Punnett, ScD, ${ }^{1}$ James $M$ Robins, MD, ${ }^{1}$ David $H$ Wegman, MD, MS, ${ }^{2}$ \\ W Monroe Keyserling, $\mathrm{PhD}^{3}$
}

\begin{abstract}
PUNNETT L, ROBINS JM, WEGMAN DH, KEYSERLING WM. Soft tissue disorders in the upper limbs of female garment workers. Scand J Work Environ Health 11 (1985) 417-425. In this cross-sectional investigation of female garment workers the prevalence of soft tissue disorders of the hands and arms was studied. The findings were compared with the prevalence of disorders in a group of female hospital employees not required to use repetitive hand motion. One hundred and eighty-eight garment workers and 76 hospital employees were surveyed by questionnaire and physical examination. The prevalences of persistent shoulder, wrist, and hand pain were significantly greater among the garment workers (rate ratio 2,4 , and 3, respectively). In both groups about $60 \%$ of the persistent hand pain was consistent with carpal tunnel syndrome (rate ratio 3 ). These associations held when the comparisons were stratified by age and by length of employment. Workers whose native language was not English were significantly less likely to report symptoms (rate ratio 0.6 ). Workers in hand sewing and trimming suffered especially high prevalences of persistent pain in all upper limb sites. Stitchers had elevated rates of pain in the shoulders, wrists, and hands. Workers ironing by hand had a significant elevation in elbow pain rates. Garment assembly tasks appear to be associated with cumulative trauma of the hands and wrists; the biomechanical features of these jobs should be studied in greater detail.
\end{abstract}

Key terms: carpal tunnel syndrome, cumulative trauma, musculoskeletal disorders, repetitive hand motion.

Workers in a large number of industries must perform rapid, stereotyped hand motions. This type of manual work has been anecdotally linked to neurological and musculoskeletal disorders such as carpal tunnel syndrome, tenosynovitis of the wrist, and nonspecific persistent hand pain for several decades in reports such as those reviewed by Hadler (11) and Kurppa et al (16). In a smaller number of recent, formal epidemiologic studies, in which assembly workers have been compared to other workers performing less repetitive tasks, the ratios of the prevalence of soft tissue disorders have ranged from 2 to 6 for workers using repetitive hand motion $(4,9,17,18,29)$.

The prevalence and incidence of soft tissue disorders in the garment industry have not been well studied. The industry employs at least 1150000 people in the United States, over $90 \%$ of whom are women. Wehrle (37) estimated that the incidence of carpal tunnel syndrome among workers with certain jobs in one upholstery plant was as high as 128 cases/million personhours worked, while the plant-wide average was 10.3 cases/million person-hours. A survey of 190 workers in seven garment shops in western Massachusetts disclosed persistent hand pain in $32 \%$ (15), as compared

1 Occupational Health Program, Harvard School of Public Health, Boston, Massachusetts, United States.

2 School of Public Health, Center for Health Sciences, University of California, Los Angeles, California, United States.

${ }^{3}$ Center for Ergonomics, University of Michigan, Ann Arbor, Michigan, United States.

Reprint requests to: Dr L Punnett, Center for Ergonomics, 1205 Beal - IOE Building, University of Michigan, Ann Arbor, MI 48109-2117, USA. with about $4 \%$ in the general population (24). Vihma et al (35) found that sewing machine operators working in mass production, with short (30-60 s) work cycles, had more musculoskeletal complaints than operators who constructed entire garments and therefore used varied rather than highly repetitive movements.

In many of the studies mentioned, the workplace data come from case series compiled from logs of reportable injury and illness of the Occupational Safety and Health Administration, inplant medical departments, or workers' compensation records. Since these sources identify late-stage disorders that prompt workers to seek medical attention, the data probably identify an incomplete subset of cases and underestimate the true rates of disease (14). Therefore, using a questionnaire and physical examination, we chose to survey directly a population of actively employed garment workers. We compared them with a group of employees believed not to be exposed to repetitive hand motion. The objectives were (i) to estimate the prevalence of persistent upper limb pain and physical findings among garment workers, (ii) to determine whether these symptoms and signs were associated with employment in this garment shop, and (iii) to identify the garment jobs, if any, in which the affected workers were concentrated.

\section{Subjects and methods}

\section{Population}

The study population consisted of workers in a garment shop near Boston where women's jackets are 
manufactured. Most of the workers are women, and a large number are first- and second-generation immigrants, primarily from Europe and Latin America. During December 1981 to January 1982 all active employees except supervisory and office personnel were recruited.

At the time of the survey there were 214 people actively employed in the garment shop. A total of 207 workers $(97 \%)$ participated in some phase of the study. Physical examinations were performed on 205 people. The questionnaire was answered by 188 workers, and the remaining 26 declined to complete it. Sufficient information was provided by 179 workers (162 women and $17 \mathrm{men}$ ) to be included in all analyses of the prevalence of persistent pain. Missing and incomplete questionnaires were due largely to language and literacy barriers and to irregular and shortened work schedules during the industry's slack season.

In the general population, carpel tunnel syndrome and de Quervain's disease are reportedly more prevalent among women (14), although there is no formal epidemiologic evidence of this (16). Since the men and women in this garment shop were largely employed in different jobs and since there were too few men in the study population (only $9 \%$ ) to analyze their results separately, the data analysis was restricted to women.

The mean age of the 162 participating female garment workers was 43 (SD 12) years, and their mean length of employment in the garment industry was 11 (SD 10) years. They were employed in the jobs of stitcher (sewing machine operator), finisher (sewing and trimming by hand), underpresser (ironing by hand), floor work (carrying work bundles), and others (shipping, operation of a fusing machine, etc). The first two job categories, which account for $86 \%$ of the study population, exposed workers to the use of highly repetitive, low force wrist and fine finger motions; finishers also use shoulder and elbow motions. Underpressers use somewhat more forceful shoulder, elbow, and wrist motions.

The reference group comprised female workers in a chronic care hospital, also in the Boston area. The first language of all of these women was English. Volunteers were recruited in January and February 1982 from all departments with workers on day and evening shifts. Employees whose jobs required four or more hours of typing per day were excluded.

There were about 190 women employed either fulltime or part-time in the hospital on the day and afternoon shifts. Of the full-time employees, $76(40 \%$ of the total) participated in the survey. The questionnaire was completed by 73 workers, and all 76 participated in the physical examinations.

The mean age of the 76 hospital workers was 41 (SD 12) years, and their mean length of employment in this hospital was 5 (SD 4) years. These women were employed in the following four job categories, broadly grouped by the nature of the physical work required: (i) registered nurses, licensed practical nurses and aides; (ii) laboratory technicians, physical and recreational therapists; (iii) laundry and food service workers; and (iv) social service and administrative employees.

\section{Examination procedure}

All the participants were examined for physical signs of soft tissue disorders in the hands or wrists. The examinations were carried out in the workplace by trained investigators using test procedures standardized in consultation with a rheumatologist, an orthopedic surgeon, and an internist with training in neurology. The test series included inspection for thenar atrophy, Tinel's sign, and Phalen's test for carpal tunnel syndrome $(25,30)$; Finkelstein's test for de Quervain's disease (tenosynovitis of the thumb extensor tendons) $(8,10)$; and examination of the thumb for degeneration of the carpo-metacarpal joint $(8,27)$.

Workers who had a positive Phalen's or Tinel's test were classified as having physical signs of carpal tunnel syndrome. Those with a positive Finkelstein's test were classified as having signs of de Quervain's disease, and those with a positive thumb rotation test were classified as having signs of thumb joint degeneration.

\section{Questionnaire}

All the workers received a self-administered questionnaire which inquired about persistent pain and numbness or tingling of the back, neck, shoulders, elbows, wrists, and hands. The key questions were based on the Arthritis Supplement Questionnaire of the National Health and Nutrition Examination Survey (24), with persistent pain defined as pain which lasted for most days for one month or more within the past year. Workers who reported symptoms either on the questionnaire or after being tested were administered a supplementary questionnaire to determine date of first onset, location, frequency, duration, and other symptom characteristics. Workers were identified as cases if they reported persistent pain, according to the study definition, on either of these two occasions. Symptoms which had occurred within the past year were considered for analysis if they were unassociated with previous injury and had begun after first employment in garment manufacturing or hospital employment.

Among the workers with persistent hand pain, symptoms were classified by location as pertaining to the median nerve, the tendons of the back of the hand, the finger and thumb joints, or the intrinsic muscles of the hand. Median nerve symptoms (pain, numbness, or tingling) were considered to be consistent with carpal tunnel syndrome if they were present at night or early in the morning or they met two of the following three criteria: (i) were accompanied by weakness in pinching or gripping, (ii) were alleviated by absence from work 
for a week or more, or (iii) were aggravated by housework or other nonoccupational tasks (25). ${ }^{4}$

Information was also obtained from the questionnaire on work history and on other determinants of risk, including past injury to the trunk or upper limb, medical and gynecological history, past exposure to neurological toxins, and alcohol consumption. In addition to current job title, the job held at time of first onset of symptoms was identified for workers who reported persistent hand or wrist pain. Six garment and four hospital workers were employed in another job in the same industry at the time of first onset of pain; in the job-specific analyses they were assigned to their job at onset of pain.

\section{Data analysis}

All the analyses were performed using the SAS software package (31). Rate (prevalence) ratios for garment versus hospital employees were computed with approximate $95 \%$ confidence intervals (22), except when the expected cell size was less than five and the exact confidence intervals were calculated, according to Miettinen's modification (21) of the traditional method (1). All p-values reported are two-sided unless otherwise noted.

To evaluate and control for potential confounding, these same comparisons were made after stratification by number of years employed, decade of age, and native language. We computed chi-square tests of linear trend (19) in the prevalence of pain in each workplace by age and by number of years employed. Standardized rate ratios were calculated with the distributions of age and years employed of the hospital workers as weights for direct comparability (23). To estimate the effect of language across the age groups, we calculated rate ratios using the estimator proposed by Rothman \& Boice (28) for cumulative incidence data with analogy to the Mantel-Haenszel estimator (20).

We examined the effect of the following endocrine changes, reported to be risk factors in respect to the symptoms of carpal tunnel syndrome: menopause, use of oral contraceptives or exogenous estrogens, pregnancy, or history of hysterectomy with bilateral ovariectomy $(9,25,33)$. The number of women with any one of these conditions was too small to consider them separately, so we grouped together all those women with one or more of the aforementioned changes. We stratified the analysis of symptoms of carpal tunnel syndrome on the presence or absence of any one of these factors and computed the MantelHaenszel chi-square test statistic and point estimate (20).

We performed a second stratified analysis of the symptoms of carpal tunnel syndrome by similarly grouping the women with a history of one or more

4 These criteria were recommended by I Kuorinka, MD, Institute of Occupational Health, Helsinki, Finland, in a personal communication in 1981. of the following systemic diseases reported to be risk factors for the syndrome: rheumatoid arthritis, diabetes mellitus, hypothyroidism, or kidney disorders $(12,25,33)$.

The job-specific prevalence of pain was calculated for four garment job categories, and summary chisquare statistics were computed for the difference among these jobs for each site of pain. Rate ratios were calculated for each of these four categories with the prevalence for all hospital workers as the expected value. Similarly, the prevalences and summary chisquare statistics were calculated for seven stitching tasks as subgroups of the stitcher category. These stitching tasks were grouped on the basis of observations of the particular hand and arm motions required by each.

We used multivariate logistic regression analysis to examine simultaneously the effects of multiple risk factors on the odds of having persistent pain in any site, in the shoulder, in the wrist, or in the hand. The independent variables of greatest interest were industry (garment or hospital) and job category. Other independent variables considered were age, number of years employed in current industry, and native language (English or other).

The regression coefficients in the logistic regression analysis were interpreted as the log odds ratios, which approximate the rate ratio in cross-sectional data. The tests of statistical significance and confidence intervals were calculated from the maximum likelihood estimates of the coefficients and their standard errors. The contribution of adding a new term to a model in a nested series was evaluated by the likelihood ratio test, which is the difference of the maximized log likelihood statistics for the models with and without the new term (6).

\section{Results}

\section{Analysis by industry}

A total of 79 garment workers and 30 hospital workers reported persistent pain, numbness, or tingling in one or more sites of the trunk or upper limbs within the past year. Five garment and five hospital workers with persistent pain had had injuries to the same site(s) within two years prior to the first onset of symptoms. Their responses for those sites were excluded. Six garment and nine hospital workers were excluded because they reported that their first onset of pain preceded employment in their current type of work. ${ }^{5}$ Therefore, there was a total of $68(42 \%)$ garment workers and $16(22 \%)$ hospital workers with prevalent persistent pain in one or more sites of the back, neck, or upper limbs.

\footnotetext{
s Seven of the symptomatic garment workers had been employed in the manufacture of leather sportswear, coats, or shoes at the time of first symptom onset. Their responses
} were not excluded. 
Table 1. Proportions of the garment and hospital workers with persistent pain, numbness, or tingling in the upper limbs and trunk.

\begin{tabular}{|c|c|c|c|c|c|c|c|}
\hline \multirow{2}{*}{$\begin{array}{l}\text { Site } \\
\text { or } \\
\text { disorder }\end{array}$} & \multicolumn{2}{|c|}{$\begin{array}{c}\text { Garment } \\
\text { workers } \\
(N=162)\end{array}$} & \multicolumn{2}{|c|}{$\begin{array}{l}\text { Hospital } \\
\text { employees } \\
(N=73)\end{array}$} & \multirow{2}{*}{$\begin{array}{l}\text { Rate } \\
\text { ratio }\end{array}$} & \multirow[t]{2}{*}{ p-Value ${ }^{a}$} & \multirow{2}{*}{$\begin{array}{l}95 \% \text { con- } \\
\text { fidence } \\
\text { interval }\end{array}$} \\
\hline & $\mathrm{N}$ & $\%$ & $\mathrm{~N}$ & $\%$ & & & \\
\hline $\begin{array}{l}\text { Any site } \\
\text { Back/neck } \\
\text { Shoulder } \\
\text { Elbowc } \\
\text { Wrist } \\
\text { Hand } \\
\text { Carpel tunnel syndrome }\end{array}$ & $\begin{array}{l}68 \\
25 \\
30 \\
10 \\
26 \\
42 \\
27\end{array}$ & $\begin{array}{r}42.0 \\
16.9 \\
19.6 \\
6.5 \\
16.8 \\
27.3 \\
18.0\end{array}$ & $\begin{array}{r}16 \\
9 \\
6 \\
2 \\
3 \\
7 \\
4\end{array}$ & $\begin{array}{r}21.9 \\
14.3 \\
8.8 \\
2.8 \\
2.8 \\
4.3 \\
10.3 \\
6.0\end{array}$ & $\begin{array}{l}1.9 \\
1.2 \\
2.2 \\
2.4 \\
3.9 \\
3.9 \\
2.7 \\
3.0\end{array}$ & $\begin{array}{l}0.003 \\
0.21 \\
0.02 \\
0.01 \\
0.005 \\
0.002 \\
0.02\end{array}$ & $\begin{array}{l}1.2-2.9 \\
0.8-1.9 \\
1.0-4.9 \\
1.2-4.2 \\
1.4-10.9 \\
1.3-5.2 \\
1.2-7.6\end{array}$ \\
\hline
\end{tabular}

a One-sided approximate test, except where noted.

b Test-based $95 \%$ confidence intervals, except where noted.

c Exact test and $95 \%$ confidence interval.

d Symptoms meeting criteria for carpal tunnel syndrome.

Table 2. Classification of persistent hand pain of garment and hospital workers by industry.

\begin{tabular}{lrrrrr}
\hline \multirow{2}{*}{ Location of pain } & \multicolumn{2}{c}{$\begin{array}{c}\text { Garment } \\
\text { workers }\end{array}$} & & \multicolumn{2}{c}{$\begin{array}{c}\text { Hospital } \\
\text { employees }\end{array}$} \\
\cline { 2 - 3 } \cline { 6 - 7 } & $\mathrm{N}$ & $\%$ & & $\mathrm{~N}$ & $\%$ \\
\hline Median nerve & 30 & $71^{\mathrm{a}}$ & & 5 & $71^{\mathrm{b}}$ \\
Thumb joint & 8 & $19^{\mathrm{c}}$ & & - & 0 \\
Dorsal tendons & 2 & $5^{\mathrm{d}}$ & & - & 0 \\
Intrinsic muscles & 1 & 2 & & - & 0 \\
Finger joints & - & 0 & & 1 & 14 \\
None of the above & 1 & 2 & & - & 0 \\
Information not available & 4 & 10 & & 1 & 14 \\
\hline Total & 42 & 100 & & 7 & 100 \\
\hline
\end{tabular}

a Includes 27 who met criteria for carpal tunnel syndrome, 11 of whom $(41 \%)$ had physical signs of the syndrome. (See the text.)

b includes four who met criteria for carpal tunnel syndrome all four had physical signs of the syndrome.

c Includes two who also had median nerve symptoms; five of the eight $(63 \%)$ had physical signs of thumb joint degeneration.

d Includes one with a history of trigger finger.

The distribution of all symptoms by site is shown in table 1. The prevalence of persistent pain in each site of the upper limbs, but not of the trunk, was elevated among the garment workers in comparison with the hospital workers.

About $56 \%$ of the symptomatic garment workers had pain in more than one site, in comparison to about $44 \%$ of the symptomatic hospital workers. The difference in these percentages of pain in one or more sites was not significant (summary chi-square $=4.8$ on 4 degrees of freedom (df), $p=0.3$ ). Pain in each site of the trunk and upper limbs was significantly $(p<0.01)$ correlated with each other site, the highest correlation coefficients being for the back and shoulder $(r=0.46)$ and for the wrist and hand $(r=0.41)$.

Thirteen of the 26 garment workers $(50 \%)$ and two of the three hospital workers $(67 \%)$ with persistent wrist pain had physical signs of de Quervain's disease. For the 42 garment and 7 hospital workers who reported persistent hand pain, the location and nature of the symptoms could be classified for most of them (table 2). Median nerve symptoms which met our screening criteria for carpal tunnel syndrome represented 64 and $57 \%$ of all persistent hand pain among the garment and hospital workers, respectively.

The age distributions of the two populations were similar $(t=1.34$ on $242 \mathrm{df}, \mathrm{p}=0.18)$. We stratified the prevalence of pain in each upper limb site by decade of age to look for age-specific differences in prevalence. There was no clear linear trend in the prevalence of pain by age among the hospital workers. Among the garment workers there were trends by age only for wrist and hand pain and symptoms of carpal tunnel syndrome; the chi-square tests for trend showed all three of these to be significant $(p<0.01)$.

Since age is a risk factor for wrist and hand pain but not strongly associated with exposure, it was expected to confound those crude rate ratios only weakly. We found no change in the age-standardized rate ratios or their corresponding confidence intervals for pain in any site or for pain in the back or neck, shoulder or elbow. The standardized rate ratios for wrist and hand pain and symptoms of carpal tunnel syndrome were slightly lower than the crude estimates $(3.5,2.4$, and 2.7 , respectively), but there was little change in the confidence intervals.

The data were stratified by length of employment (years since first exposure) for an assessment of whether the association between pain and type of work was confounded by length of employment. The standardized rate ratio for each site was virtually identical to the crude measure of association in table 1 . We also looked for evidence of an increasing trend in rate ratio with length of employment, as a proxy for latency. The prevalence of pain in any site among the garment workers did not show a linear trend with years of employment. Analysis for pain in each site in turn produced similar results, and the chi-square tests for trend were not significant for any of these. The prevalence of pain in any site did increase by years worked among the hospital employees, and the chisquare test for trend was significant $(p=0.038)$.

Next we performed stratified analyses to examine the potential effect of reported hormonal and disease risk 
Table 3. Prevalence of symptoms of carpal tunnel syndrome (CTS) among the garment and hospital workers by hormonal status.

\begin{tabular}{|c|c|c|c|c|c|c|}
\hline \multirow[b]{2}{*}{ Industry } & \multicolumn{3}{|c|}{ Hormonal condition present } & \multicolumn{3}{|c|}{ Hormonal condition absent } \\
\hline & $\begin{array}{c}\text { CTS } \\
\text { symptoms }\end{array}$ & $\begin{array}{l}\text { No CTS } \\
\text { symptoms }\end{array}$ & Total & $\begin{array}{c}\text { CTS } \\
\text { symptoms }\end{array}$ & $\begin{array}{l}\text { No CTS } \\
\text { symptoms }\end{array}$ & Total \\
\hline $\begin{array}{l}\text { Garment } \\
\text { Hospital }\end{array}$ & $\begin{array}{r}10 \\
1\end{array}$ & $\begin{array}{l}22 \\
25\end{array}$ & $\begin{array}{l}32 \\
26\end{array}$ & $\begin{array}{r}13 \\
3\end{array}$ & $\begin{array}{l}98 \\
36\end{array}$ & $\begin{array}{r}111 \\
39\end{array}$ \\
\hline Total & 11 & 47 & 58 & 16 & 134 & 150 \\
\hline \multicolumn{4}{|c|}{$\begin{array}{l}\text { Rate ratio } \\
\text { Mantel-Haenszel chi square }=2.1^{\star} \\
\text { Pooled rate ratio }=3.1,95 \% \text { confidence interval }=1.2-8.4\end{array}$} & \multicolumn{2}{|c|}{1.5} & \\
\hline
\end{tabular}

a Symptoms meeting criteria for carpal tunnel syndrome.

${ }^{*} \mathrm{p}<0.01$.

Table 4. Rate ratios of persistent upper limb pain among the garment workers, by job title, as compared with those of the hospital workers.

\begin{tabular}{|c|c|c|c|c|c|c|c|}
\hline \multirow{2}{*}{ Job category } & \multirow{2}{*}{$\begin{array}{l}\text { Number } \\
\text { of workers }\end{array}$} & \multicolumn{6}{|c|}{ Site of pain or type of disorder } \\
\hline & & Any site* & Shoulder & Elbow & Wrist & Hand* & CTS ${ }^{a *}$ \\
\hline $\begin{array}{l}\text { Stitcher } \\
\text { Finisher } \\
\text { Underpresser } \\
\text { Otherb }\end{array}$ & $\begin{array}{r}117 \\
19 \\
12 \\
14\end{array}$ & $\begin{array}{l}1.6^{* \star} \\
3.8^{\star \star \star} \\
1.1 \\
2.3^{\star \star}\end{array}$ & $\begin{array}{l}2.0^{\star \star} \\
4.0^{\star \star \star} \\
2.1 \\
1.9\end{array}$ & $\begin{array}{l}1.6 \\
5.6^{\star \star} \\
6.0^{\star \star \star \star} \\
0\end{array}$ & $\begin{array}{l}3.4^{* \pi *} \\
8.3^{* \star \star} \\
4.7 \\
1.9\end{array}$ & $\begin{array}{l}2.2^{\star \star} \\
5.9^{\star \star \star} \\
1.6^{*} \\
3.0^{\star \star}\end{array}$ & $\begin{array}{l}2.5^{\star \star} \\
7.9^{\star \star \star} \\
1.5 \\
2.8\end{array}$ \\
\hline
\end{tabular}

a Symptoms of carpal tunnel syndrome (CTS).

b Includes floor help, shippers, and unknown.

* $p \leq 0.01$ (chi square on three degrees of freedom for difference among four proportions); * $p \leq 0.05$ (one-sided approximate test); ${ }^{\star \star \star} p \leq 0.01$ (one-sided approximate test); ${ }^{\star \star \star *} p \leq 0.05$ (one-sided exact test).

factors for carpal tunnel syndrome on the prevalence of these symptoms. In the stratum with one or more hormonal conditions there was a larger proportion of women with symptoms of the syndrome but fewer garment workers than in the stratum without hormonal conditions (table 3 ). Thus change in hormonal status was positively associated with symptoms of the syndrome but negatively associated with employment in the garment shop. The association between syndrome symptoms and garment work was stronger in the stratum with hormonal conditions present.

In contrast, history of disease was negatively associated both with symptoms of carpal tunnel syndrome and with employment in the garment shop. Of the diseases reported in the literature as risk factors for the syndrome, rheumatoid arthritis, diabetes, gout, thyroid, and kidney condition diagnoses were reported by the subjects in this study. The rate ratio in the nondisease stratum could not be estimated because of small numbers and a zero cell. However, the pooled rate ratio of 3.4 (95\% confidence interval $1.4-8.4$ ) was not very different from the crude estimate or from the pooled estimate in table 3.

Most of the women employed in the garment shop were native speakers of languages other than English: Greek (46\%), Italian (20\%), Spanish (9\%), and other $(12 \%)$. When the prevalence of persistent pain was analyzed within the group of garment workers according to whether or not they were native English speakers, the nonnative English speakers were significantly less likely to report pain (rate ratio 0.6 , $\mathrm{p}<0.05)$. The native English speakers were older than the nonnative English speaking workers (mean ages 49 and 42 years, respectively; $p=0.03$ ). When stratified by decade of age, the nonnative English speakers were still less likely to report pain (pooled rate ratio 0.7 ), although the difference was no longer statistically significant $(p=0.21)$.

If the comparison between the garment and hospital workers were restricted to native English speakers, the rate ratio for persistent pain in any site would increase from 1.9 to 2.8 (95\% confidence interval $1.6-5.0)$. This estimate does not change markedly when standardized to the age distribution of the hospital workers (rate ratio 2.6 ).

\section{Analysis by job title}

We examined the prevalence of symptoms by job title because we had observed that each set of tasks resulted in a unique combination of ergonomic stresses to the upper limb. The rate ratios for the four garment job categories, when compared to all hospital workers, are shown in table 4 . The summary chi-square statistic for differences in prevalence among the garment jobs was significant for pain in any site, for persistent hand pain, and for symptoms of carpal tunnel syndrome. The garment workers in the job of finishing had especially and significantly high prevalences of pain in all upper limb sites. Stitchers had elevated rate ratios for shoulder, wrist, and hand pain and symptoms of carpal tunnel syndrome that were statistically significant. Under- 
Table 5. Rate ratios for persistent upper limb pain among stitchers, by task, as compared with that among hospital workers.

\begin{tabular}{lcccccc}
\hline \multirow{2}{*}{ Stitching task } & \multirow{2}{*}{$\begin{array}{c}\text { Number } \\
\text { of workers }\end{array}$} & \multicolumn{5}{c}{ Site of pain or type of disorder } \\
\cline { 3 - 7 } & & Shoulder* & Elbow* & Wrist* & Hand* & CTS \\
\hline Straight stitch & 32 & $3.9^{* * *}$ & 2.4 & $5.8^{* * *}$ & 1.9 & $2.9^{* *}$ \\
Topstitch & 9 & $5.0^{* *}$ & 0 & $5.2^{* * * *}$ & $3.2^{* * * *}$ & 2.1 \\
Setting linings & 15 & 1.6 & $7.7^{* *}$ & $4.7^{* *}$ & $3.9^{* * *}$ & $5.6^{* * *}$ \\
Setting pockets & 10 & 1.1 & 0 & 4.7 & $4.9^{* * *}$ & $5.0^{* *}$ \\
Otherb & 51 & 0.6 & 0 & 0.9 & 1.0 & 0.7 \\
\hline
\end{tabular}

a Symptoms of carpal tunnel syndrome (CTS).

b Includes setting collars, setting sleeves, and making linings.

* $p<0.01$ (chi square on six degrees of freedom for differences among seven proportions); ** $p \leq 0.05$ (one-sided approximate test); ${ }^{\star \star \star} p \leq 0.01$ (one-sided approximate test); ${ }^{\star \star \star \star} p \leq 0.05$ (one-sided exact test).

Table 6. Odds ratios (OR) and $95 \%$ confidence intervals $(95 \% \mathrm{Cl})$ from the logistic regression analysis of the odds of persistent pain at any site among the garment workers.

\begin{tabular}{lll}
\hline Independent variable & OR & $95 \% \mathrm{Cl}$ \\
\hline Garment work (native English- & & \\
speaking workers) & & \\
Garment work (nonnative English $^{\mathrm{s}}$ & 5.5 & $1.8-17.3$ \\
speaking workers) & 2.3 & $1.2-4.5$ \\
Age (10 years) $^{\mathrm{b}}$ & 1.6 & $1.2-2.1$ \\
Length of employment (10 years) $^{\mathrm{c}}$ & 0.9 & $0.7-1.1$ \\
\hline
\end{tabular}

Model chi square ( 4 degrees of freedom) $=24.46$ p-value $=0.0001$

a Average effect for garment workers in comparison with hospital workers - age and number of years worked having been controlled for.

b Average effect of ten years of age - shop, $n$ umber of years worked, and language having been controlled for.

c Average effect of ten years of employment - shop, number of years worked, and language having been controlled for.

pressers had a significantly elevated rate ratio for persistent elbow pain.

A comparison of age distributions by job category showed that finishers, the job with the highest rate ratios for persistent pain, were older than the other garment workers. The rate ratios for finishers, when standardized to the age distribution of the hospital workers, did not change for shoulder or elbow pain but were somewhat lower for wrist and hand pain than those seen in table 4 (4.7 and 3.6, respectively).

Among the garment workers, there were no native English speakers employed as finishers, the job with the highest prevalence of persistent pain. We pooled the data across the other three garment job categories to reestimate the effect of language while controlling for job and found that the nonnative English speakers were still less likely to report pain (rate ratio 0.7 ).

Four specific stitching assembly tasks had an elevated prevalence of pain in at least one upper limb site. The tasks which did not show an excess prevalence for any site, relative to the hospital workers, were pooled to form one group ("other stitchers") for more concise presentation of the data (table 5). The summary chi-square statistics indicated significant differences among these stitching tasks for shoulder, elbow, wrist, and hand pain. The stitchers who set linings into the jackets appeared to have particularly elevated rates of lower arm pain.

\section{Multiple logistic regression analysis}

In the logistic regression analysis of persistent pain in any site, the independent variables which made a statistically significant contribution to the model were industry (garment versus hospital), language (English versus other), and age (in years) (table 6). In this model, employment in the garment industry had a rate ratio greater than 5 , as estimated by the odds ratio, for native English speakers after control for age and length of employment.

The nonnative English speaking workers were still found to underreport symptoms when the effects of age and job were taken into account. Age was a weak but statistically significant predictor of risk, with a rate ratio of less than 2 for a 10 -year increase in age. The coefficient for length of employment was not significant when the other variables were in the model. When length of employment was dropped from the model, the other coefficients changed very little. The likelihood ratio test for the difference between the model shown in the table and the model without a term for length of employment was not statistically significant (chi-square 0.62, $\mathrm{p}=0.43$ ).

We also constructed the model using job title instead of workplace as a proxy for exposure. This model explained more of the variability in the data (correlation coefficient 0.33 , compared with 0.24 for the model in table 6 after length of employment was dropped). The rate ratios for the jobs of stitching, finishing, and other garment work compared with hospital work were $4.8,42.6$, and 12.2 , respectively ( $\mathrm{p}<0.01$ for each). Underpressers had a rate ratio of only $1.4(p=0.72)$, a value consistent with the results in table 4 . The estimated effects of language and age were very similar in magnitude and statistical significance to those in the previous regression analysis.

The logistic regression analysis on persistent shoulder pain gave similar estimates of the rate ratio for garment work and language, but age was not a significant risk factor for this outcome. For persistent wrist and hand pain and symptoms of carpal tunnel syndrome, garment work and age had similar coefficients 
as in the first analysis, but language was not a significant predictor. The multivariate analysis of symptoms of carpal tunnel syndrome showed that neither disease nor change in hormonal status was a significant risk factor.

\section{Discussion}

The prevalence of persistent shoulder, wrist, and hand pain among female garment workers was markedly and significantly elevated in comparison with that of female hospital workers. Increased rate ratios were determined for all upper limb sites in the garment job category of finisher. Stitchers had elevated rates of hand and wrist pain; underpressers had elevated rates of elbow and wrist pain. The prevalence of symptoms of carpal tunnel syndrome was also found to be significantly elevated among the stitchers and finishers. These associations held when we controlled for the effects of age, length of employment, and reported systemic risk factors for carpal tunnel syndrome. Multiple logistic regression analysis confirmed these associations when all other measured risk factors were controlled for simultaneously.

Workers in certain stitching tasks, especially the setting of linings into jackets, had a much higher prevalence of persistent pain than workers performing other tasks. Ideally, we would have constructed prior hypotheses as to which sites of the upper limb are likely to be at risk in each task. This procedure would have been difficult, however, without biomechanical analyses of the jobs in question, since no jobs in this garment shop appeared to be completely free of ergonomic stressors. Therefore we could not avoid the problem of multiple comparisons in the testing of the statistical significance of the rate ratios for each job.

The choice to exclude workers whose pain began when they were employed in other industries is a conservative one. If a worker had pain caused by a previous job and it was reaggravated by her current one, that job could still be considered stressful to the soft tissues. However, for clarity in studying the etiology of the disorders, we sought to identify only biomechanical stresses severe enough to cause new (incident) pain.

The garment workers seldom reported pain in only one site of the upper limb. This occurrence could have resulted from a small number of people tending to complain more readily or from the fact that garment manufacturing jobs cause ergonomic stress at multiple sites simultaneously. The symptoms were reported in combinations that are reasonable given the nature of the biomechanical stressors present in these tasks; for example, a job which is stressful to the shoulders is likely also to affect the neck and upper back. These findings imply that "overreporting" at random did not occur, but that the observed clustering of symptoms reflects the simultaneous stressing of biomechanically related joints. It was also our subjective evaluation that these employees were, in general, reluctant to report symptoms, a reluctance overcome only in the case of genuine pain.

The questionnaire used in this study was translated into Greek and Spanish, and the interviews were conducted in these languages or Italian when necessary. Nevertheless, it is still possible that difficulty in understanding the questionnaire or cultural differences in willingness to discuss health problems could have confounded the reporting of pain and other symptoms.

Brodsky (7) has summarized the mixed results of research on the relation between illness behavior and culture or ethnicity. While several researchers have found ethnic differences in the reporting of pain, another investigator found no such differences after controlling for the level of education of the subjects. Education is not a variable that we collected information on in the present study, but we would not expect it to vary greatly among these garment workers. Ethnicity may also act as a proxy for other variables, including historical and political experience; for example, several garment workers were hesitant at first to be interviewed, later explaining that they had experienced repressive labor conditions in the past in other countries.

The rate ratio for upper limb pain in garment workers was higher when the comparison was restricted to individuals whose native language is English, even after standardization for age. Since our real interest was in the effect of specific garment tasks on soft tissue pain, we considered the effect of language further in the job-specific analyses. The association between language and symptom reporting held across job categories, so it genuinely appears to confound these data.

There were no native English speakers employed as finishers, the job with the highest prevalence of symptoms. However, the pooled rate ratio across the other three garment jobs was still greater for native English speakers. If the women employed as finishers were actually less likely to report symptoms because they were not native English speakers, the association of persistent pain with finishing work may be biased downward as a result. This possibility suggests that the rate ratio for finishers would be even higher if they were of the same ethnic background as the hospital workers.

The level of participation among the hospital workers was lower than among the garment workers. In order for this difference to bias the study results and cause a spurious association, there would have had to be a systematic selection of asymptomatic hospital workers into the study. We have no reason to believe that this was the situation.

Since the prevalence of soft tissue disorders in the general population is higher in older age groups (14), we expected to see a similar trend in the prevalence of persistent pain in the two groups studied. We also 
would have expected an increasing trend by number of years worked, if age were a risk factor and symptoms were cumulative over time, even if employment in the garment industry were not associated with a higher risk of soft tissue pain. If the pain were work-related and cumulative and if selection bias were not a major factor, we would expect a linear increase in the rate ratio with increasing length of employment, as with other work-related disorders.

The fact that no such trend with length of employment was apparent suggests, among other possible explanations, that workers with persistent pain might be more likely to'leave employment. A cross-sectional study is vulnerable to this type of selection bias, often somewhat imprecisely referred to as the "healthy worker effect" $(13,36)$. Another form of selection bias which might have operated is that employees absent because of work-related health problems would be less likely to be included in the survey. Either of these possibilities would bias the estimated measure of association towards the null value.

If older, more experienced workers are more likely to develop upper limb pain and then leave employment, the consequences for a cross-sectional study include not only underestimation of the prevalence of persistent pain in the study population but also underestimation of the severity of this pain. The very nature of the study design, while obtaining greater sensitivity to nondisabling pain in active workers, necessarily excludes workers with disabling pain who are no longer able to work. In order for the full progression and range of occupational soft tissue disorders to be studied, a cohort must be defined and followed over time, and those cohort members who leave employment for any reason must be included in the study follow-up.

The excess of persistent upper limb pain in the studied garment workers appeared to be work-related. This finding is consistent with the observations of other authors that workers who must use repetitive hand and wrist motions in their jobs develop soft tissue disorders. The finding that garment workers in certain jobs have an especially high prevalence of pain suggests that these jobs are the most stressful to the upper limbs. These jobs should be described in greater detail with respect to their biomechanical features so that the ergonomically stressful features of each can be identified.

Clinical case series and biomechanical and histological studies have generated hypotheses about the causes of disorders such as carpal tunnel syndrome and de Quervain's disease $(2,3,5,10,26,32,34)$. Epidemiologic research that measures the parameters of biomechanical stress could be used to evaluate these associations; it would also allow the generalization of study findings beyond the job titles in a single garment shop to other shops and potentially to other industries where workers must also perform repetitive hand motions.

\section{Acknowledgments}

During this investigation Dr Punnett was supported by a National Institute of Environmental Health Sciences National Research Service Award (5T32 ES07069) from the Harvard School of Public Health.

The authors thank the employees of Domenico's and Domenic Vincenzo; Ms P Bevins and Ms M Peretsman of the International Ladies' Garment Workers' Union; and Ms N Fox, Mr J Barmack, and the employees of the Norfolk County Hospital for their cooperation with this survey. Ms C Pidcock, Ms M Lyndon, Ms D Plantamura, Ms A Fidler, Ms L Beyer, Ms T Fabens, Mr K Tsakmalis, Ms A Nezeriotis, Ms D Spiegelman, and Ms L Pothier provided invaluable assistance with the data collection and analyses. We also thank Drs RR Monson, RH Goldman, JJ Canoso, and $\mathrm{J}$ Upton for their clinical and technical advice.

\section{References}

1. Armitage P. Statistical methods in medical research. Blackwell Scientific Publications, Oxford 1971.

2. Armstrong TJ, Castelli WA, Evans FG, Diaz-Perez R. Some histological changes in carpal tunnel contents and their biomechanical implications. J Occup Med 26 (1984) 197-201.

3. Armstrong TJ, Chaffin DB. Some biomechanical aspects of the carpal tunnel. J Biomech 12 (1979) 567-570.

4. Armstrong TJ, Chaffin DB. Carpal tunnel syndrome and selected personal attributes. J Occup Med 21 (1979) $481-486$.

5. Brain W, Wright A, Wilkson M. Spontaneous compression of both median nerves in the carpal tunnel. Lancet 1 (1947) 277-282.

6. Breslow NE, Day NE. Statistical methods in cancer research. Volume 1 (The analysis of case-control studies). International Agency for Research on Cancer, Lyon 1980.

7. Brodsky CM. Culture and disability behavior. West $\mathbf{J}$ Med 139 (1983) 892-899.

8. Cailliet RD. Hand pain and impairment. Third edition. FA Davis Company, Philadelphia, PA 1982.

9. Cannon LJ, Bernacki EJ, Walter SD. Personal and occupational factors associated with carpal tunnel syndrome. J Occup Med 23 (1981) 255-258.

10. Finkelstein $H$. Stenosing tendovaginitis at the radial styloid process. J Bone Joint Surg 12 (1930) 509-540.

11. Hadler NM. Industrial rheumatology. Arthritis Rheum 20 (1977) 1019-1024.

12. Herbison GJ, Teng C, Martin JH, Ditunno JF. Carpal tunnel syndrome in rheumatoid arthritis. Am J Phys Med 52 (1973) 68-74.

13. Hernberg S. Evaluation of epidemiologic studies in assessing the long-term effects of occupational noxious agents. Scand J Work Environ Health 6 (1980) 163-169.

14. Kelsey JL. Epidemiology of musculoskeletal disorders. Oxford University Press, New York, NY 1982.

15. Keyserling WM, Donoghue JL, Miller AB, Punnett L. Repetitive trauma disorders in the garment industry. Department of Environmental Health Sciences, Harvard School of Public Health, Boston, MA 1982. (Technical report, NIOSH contract \# PO 81-3220).

16. Kurppa K, Waris P, Rokkanen P. Peritendinitis and tenosynovitis: A review. Scand J Work Environ Health 5 (1979): suppl 3, 19-24.

17. Luopajärvi T, Kuorinka I, Virolainen $M$, Holmberg $M$. Prevalence of tenosynovitis and other injuries of the upper extremities in repetitive work. Scand J Work 
Environ Health 5 (1979): suppl 3, 48-55.

18. Maeda K, Hunting W, Grandjean E. Localized fatigue in accounting-machine operators. J Occup Med 22 (1980) $810-816$.

19. Mantel N. Chi-square tests with one degree of freedom: Extension of the Mantel-Haenszel procedure. J Am Stat Assoc 59 (1963) 690-700.

20. Mantel N, Haenszel W. Statistical aspects of the analysis of data from retrospective studies of disease. J Nat Cancer Institute 22 (1959) 719-748.

21. Miettinen OS. Comment. J Am Stat Assoc 69 (1974) 380-382.

22. Miettinen OS. Estimability and estimation in casereferent studies. Am J Epidemiol 103 (1976) 226-235.

23. Monson RR. Occupational epidemiology. CRC Press, Inc, Boca Raton, FL 1980, p 79.

24. National Center for Health Statistics. Basic data on arthritis in adults ages $25-74$ years, United States, 1971-1975. US Department of Health, Education and Welfare, Hyattsville, MD 1979. (National health and nutrition examination survey I, series 11, no 213; DHEW publication no (PHS) 79-1661).

25. Phalen GS. The carpal tunnel syndrome: Seventeen years' experience in diagnosis and treatment of 654 hands. J Bone Joint Surg 48A (1966) 211-228.

26. Phalen GS. The carpal tunnel syndrome: Clinical evaluation of 598 hands. Clin Orthop 83 (1972) 29-40.

27. Polley HF, Hunder GG. Rheumatologic interviewing and physical examination of the joints. Second edition. WB Saunders Company, Philadelphia, PA 1978.

28. Rothman KJ, Boice JD. Epidemiologic analysis with a programmable calculator. National Institutes of Health,
Washington, DC 1979, chapter 3, formulas 7 and 17. (Publication no 79-1649).

29. Roto P, Kivi P. Prevalence of epicondylitis and tenosynovitis among meatcutters. Scand $\mathbf{J}$ Work Environ Health 10 (1984) 203-205.

30. Sheon RP, Moskowitz RW, Goldberg VM. Soft tissue rheumatic pain: Recognition, management, prevention. Lea \& Febiger, Philadelphia, PA 1982.

31. Statistical Analysis System Institute, Inc. SAS user's guides. Box 8000, Cary, NC 1982.

32. Smith E, Sonstegard D, Anderson W. Carpal tunnel syndrome: Contribution of flexor tendons. Arch Phys Med Rehabil 58 (1977) 379-385.

33. Taylor N. Special review: Carpal tunnel syndrome. Am J Phys Med 50 (1971) 192-211.

34. Tichauer ER. Some aspects of stress on forearm and hand in industry. J Occup Med 8 (1966) 63-71.

35. Vihma $T$, Nurminen $M$, Mutanen P. Sewing-machine operators' work and musculo-skeletal complaints. Ergonomics 25 (1982) 295-298.

36. Wang J-D, Miettinen OS. Occupational mortality studies: Principles of validity. Scand J Work Environ Health 8 (1982) 153-158.

37. Wehrle J. Chronic wrist injuries associated with repetitive hand motions in industry. Department of Industrial and Operations Engineering, University of Michigan, Ann Arbor, MI 1976. (Occupational health and safety technical report).

Received for publication: 25 January 1985 